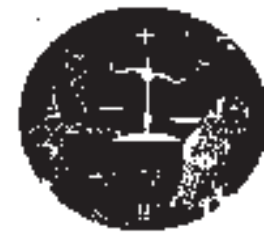

\title{
Criança não é brinquedo! A DEVOLUÇÃO DE CRIANÇAS E ADOLESCENTES EM PROCESSOS ADOTIVOS
}

\section{Alberta Emília Dolores de Goes*}

\begin{abstract}
Resumo: Este artigo tem como objetivo apresentar a processualidade da adoção de crianças e adolescentes e os fatores que levam os pretendentes à adoção à devolução destas ao Judiciário, ainda durante o estágio de convivência. Evidencia, ainda, situações relativas à adoção de crianças no que tange à legislação, ao preparo dos futuros pais adotivos e ao trabalho interprofissional desenvolvido pela equipe da Vara da Infância e Juventude, com base na experiência profissional acumulada no Tribunal de Justiça/SP.
\end{abstract}

Palavras-chave: Adoção. Devolução. Crianças e adolescentes. Serviço Social.

\section{Children are nothing to play with! The return of children and adolescents in adoption process.}

Abstract: This article aims to present the adoption process of children and adolescents and the factors that lead applicants to return them to the legal system even during the stage of coexistence. It also demonstrates situations related to the adoption of children concerning legislation, to the preparation of prospective adoptive parents and to the multi-professional work held by the staff from the Children and Youth Court, based on the work experience gathered in the Court of Justice/SP.

Keywords: Adoption. Return. Children and Adolescents. Social Service.

* Mestre em Serviço Social pela Pontifícia Universidade Católica (PUC-SP), Assistente Social Judiciária na Vara da Infância e Juventude do TJ/SP e Docente no curso de Serviço Social da Universidade Santo Amaro (UNISA/SP).

\section{INTRODUÇÃO}

Este artigo apresenta o resultado da pesquisa de dissertação de mestrado em Serviço Social (Des) Caminhos da adoção: a devolução de crianças e de adolescentes em famílias adotivas pela PUC-SP, que teve como principal disparador a nossa atuação como assistente social na Vara da Infância e Juventude do Tribunal de Justiça do Estado de São Paulo. O 'que fazer cotidiano' provocou as nossas inquietações, além do desejo de compreender melhor os processos relacionados à adoção de crianças e adolescentes.

Netto (1991, apud DINIZ, 2010, p. 42) nos traz uma importante contribuição para a reflexão sobre o desenvolvimento deste estudo a partir do nosso cotidiano profissional:

o desenvolvimento do espírito crítico e de análise, aliado à instrumentalização necessária para a atividade profissional, 
torna-se objetivo e meta para o assistente social que quer romper com o pragmatismo, ainda muito presente na profissão,

e pensar a sistematização da prática como um dos procedimentos básicos à construção teórica para a apropriação do cotidiano. Em outras palavras, dimensionamos a pesquisa em Serviço Social como um exercício fundamental, útil e estimulante na construção de um projeto profissional consciente do seu perfil intelectual.

Nesta direção, a reflexão de Diniz acerca da atuação profissional se mostra bastante oportuna:

Diante das mudanças profundas que abrangem todas as esferas da vida social, principalmente nas duas últimas décadas, colocase, por exemplo, a questão: de que modo o Serviço Social vem se legitimando como prática institucionalizada na sociedade, frente às necessidades sociais derivadas das contradições das relações sociais? Ou, do ponto de vista da capacitação profissional, como dar conta das questões mais gerais e teóricas, que não estão postas imediatamente na diversidade dos fatos sociais, objetivados numa prática cotidiana? E, com a intenção de traçar novos recortes teóricos e empíricos, dimensionados na função social da pesquisa, quais mecanismos de investigação da realidade são utilizados pelo Serviço Social, e qual é a legitimidade de seus produtos para a construção de um perfil profissional que venha atender às demandas atuais da sociedade, coerente com uma prática critica? (2010, p. 4142).

Assim, no Judiciário, as questões que se colocam para o profissional direcionam-se, principalmente, à reflexão, entre outras questões, sobre: como a nossa atuação pode se desenvolver na perspectiva do direito e da justiça social? Como contribuir para uma cultura que se fundamente nessa direção? E, ainda, como materializar o projeto ético-político-profissional?

Deste modo, apoiados no cotidiano profissional e em busca de uma compreensão mais ampla da questão estudada, utilizamos a pesquisa como uma ferramenta que nos permitiu perceber aspectos da universalidade das questões encontradas nos processos de adoção que nos escapam quando a ação se limita à singularidade de cada situação ou de cada caso. Nessa direção, nosso ponto de partida se direcionou à reflexão de que nenhuma pesquisa é neutra: daí deriva a nossa compreensão sobre os processos de adoção em um país como o Brasil, no sentido de uma reflexão mais ampliada do ponto de vista social.

A nossa escolha se deu pelo entendimento de que, em uma sociedade de classes e em um país tão desigual como o Brasil, os processos de adoção estão submetidos e condicionados a um contexto de desigualdade social. Percebemos então que, quando crianças são colocadas em famílias substitutas (adotivas), na maioria das vezes isso ocorre pela vulnerabilidade social a que estão expostas as famílias pobres, bem como pela presença deficiente de proteção social por parte do Estado, por intermédio de políticas públicas, e pela falta de uma cultura de convivência familiar e comunitária que garanta à criança e/ou ao adolescente a permanência em sua própria família.

Nessa perspectiva, os processos de adoção podem ser vistos tanto como mais uma forma de violar direitos, se não forem realmente esgotadas todas as possibilidades de retorno da criança à sua família de origem, quanto como um modo alternativo para a garantia de convivência familiar e comunitária, de direitos e de cidadania para crianças e adolescentes.

Temos que verificar e questionar como estão concebidas as políticas de proteção às famílias, antes de propor alternativas de adoção para os seus filhos e filhas, mesmo sabendo que a possibilidade do exercício da maternidade e da paternidade não se reduz a aspectos econômicos e materiais. Do contrário, pode-se cair em medidas paliativas institucionalizadas para enfrentar o descaso por famílias pobres e abandonadas, adotando um caráter excludente e compensatório, apesar da aparente benevolência contida no ato institucional dos processos adotivos. (MARQUES, 2011, p. 32).

Por outro lado, do ponto de vista do exercício profissional, nos casos de adoção o assistente social atua diretamente nessa processualidade. Trata-se de um desempenho bastante complexo, em que o profissional é convocado sobremaneira para uma 
performance mais interventiva - diferentemente das outras demandas colocadas ao profissional na área da Justiça, em que opera principalmente como perito (com ênfase na elaboração de relatórios, laudos e pareceres). Assim, o profissional irá atuar junto às famílias de origem, com as crianças/adolescentes, nos processos para a tentativa de reintegração familiar e/ ou destituição do poder familiar, nos processos de avaliação e preparo dos pretendentes e, diretamente, nos processos de adoção.

Quanto à adoção de crianças, destacamos que, na última década, tivemos o acirramento das discussões em torno dessa temática, com reflexões que apontaram inclusive para a revisão do sistema de proteção social. Essas discussões fundamentaram algumas das alterações recentes no ECA - Estatuto da Criança e Adolescente -, por intermédio da Lei 12010 de agosto de 2009, nomeada popularmente como Nova Lei de Adoção.

Juridicamente reconhecida como Lei da Convivência Familiar e Comunitária, veio reforçar a necessidade de esforços sociais e institucionais para a preservação dos vínculos e da convivência familiar, definindo que somente em casos excepcionais e extraordinários se justifica a medida de colocação de criança/adolescente em família substituta, ou seja, em adoção. Entretanto, percebemos que ainda há muitos desafios no sentido da implementação de uma política efetiva para que os reais interesses das crianças e dos adolescentes sejam garantidos, especialmente para aqueles que se encontram em situação de vulnerabilidade social.

Na prática profissional, encontramos inúmeras dificuldades para a garantia desses direitos, e essas dificuldades desencadearam questões cuja superação tem sido nossa preocupação constante, gerando, principalmente, o nosso desejo pelo estudo da temática atual. Entre os desafios enfrentados, destacamos as situações de diversas famílias que, no contexto do processo de adoção, se encontram em estágio de convivência (período de adaptação da criança/ adolescente aos pretendentes à adoção, que antecede a sentença de adoção e não tem um prazo predeterminado de duração).

Essas famílias, ao se deparar com os primeiros problemas cotidianos e/ou relacionados com a criança, por vezes manifestam ao Judiciário o desejo de sua devolução.

Embora essa situação seja usualmente pouco divulgada, é bastante recorrente e compreendemos que esse comportamento viola os direitos de crianças e de adolescentes (vitimizados com um novo abandono) e surpreende juízes, promotores e equipes técnicas das Varas da Infância e Juventude.

\footnotetext{
A idealização da adoção na nossa sociedade impossibilita a discussão não só sobre as desigualdades sociais existentes no país, mas, sobretudo, sobre os conflitos, as discriminações e as tensões que são inerentes aos processos de adoção. Consequentemente prevalecem posições antagônicas sobre essa realidade: de um lado, há aqueles que tendem a achar que tudo será lindo e maravilhoso; de outro, aqueles que pensam que o filho adotivo é sinônimo de relações problemáticas. (SILVA, 2011, p. 13).
}

Acreditamos que no enredo da temática adoção há ainda muitos preconceitos, mitos e medos que passam por muitas crenças e, dentre elas, a ideia de que ter filhos que não sejam pelas vias biológicas 'naturais', ou ainda pelos laços consanguíneos, venha a ser uma 'loucura', ou uma grande 'bondade', que se baseia, na maioria das vezes, em uma lógica que inevitavelmente coloca a situação da adoção, ou do filho adotivo, como problemática.

\footnotetext{
Profissionais que atuam na área da adoção chamam a atenção para a existência de uma visão distorcida na sociedade, que acarreta a associação da adoção a problemas e fracassos. Em contrapartida, tem sido frequente o aumento de grupos e organizações engajados na divulgação desse tema e na luta pela desmistificação de conceitos errôneos existentes ou já cristalizados na sociedade. Atualmente, diversos fóruns de debates sobre o tema da adoção têm privilegiado difundir a "cultura da adoção", com o objetivo de proporcionar um lar para crianças que aguardam a sua inclusão em uma nova estrutura familiar, sem que esse processo seja mediado por
} 
imposições de saúde, cor, gênero, raça, idade. Isso ocorre porque a adoção, no Brasil, ainda é comumente vista como solução para a infertilidade, constituindo uma das razões para a procura maciça de bebês. Desta forma, a inserção de crianças e jovens em um novo lar tem sido confundida com o desejo e a tentativa de apagar as origens (negar ou ocultar o seu nascimento biológico em outra família, negar a adoção em si mesma, ocultála etc.). Assim, o reconhecimento de diversos recortes que compõem essa ampla temática da adoção de crianças e jovens (idealização de família, perfil das crianças para adoção, perfil das famílias biológicas e dos adotantes, os critérios de seletividade - idade, sexo, cor, saúde - das crianças nas instituições, os avanços no campo do direito, as representações que se constroem nos meios de comunicação, na literatura, entre outros) coloca-nos frente a frente com a luta contra as desigualdades sociais e pela conquista do respeito à infância digna. (SILVA, 2011, p. 10-11).

Assim, ao buscar referências e informações acerca dos processos de devolução de crianças e de adolescentes em estágio de convivência, encontramos parcas informações, falta de sistematização de dados, enfim, ausência de um levantamento nacional e, por vezes, local acerca da questão.

Coacley (2005, apud Souza, 2012, p. 13) aponta que não há no Brasil estatísticas precisas sobre a situação, mas os dados americanos (o povo que mais faz adoção no mundo) mostram uma média de $3 \%$ a $12 \%$ de interrupções nas adoções; e quando se analisam os dados apenas entre adoções tardias (adolescentes de 12 a 17 anos) o percentual pode subir para $25 \%$ de interrupções.

Embora entendamos que a palavra devolução possa causar certo desconforto, principalmente por tratarmos de situações relacionadas a crianças/ adolescentes, optamos por utilizá-la, principalmente pelo impacto que esta situação causa às crianças que a vivenciam.

Devolução é uma palavra ampla e generalizada para este fenômeno e contempla pelo menos dois casos distintos: a "interrupção" e a "dissolução". A literatura internacional denomina "interrupção" da adoção quando os adotantes desistem de completar o processo antes de a adoção ser legalmente efetivada (esse período de efetivação não ultrapassa seis meses em países desenvolvidos, diferentemente do Brasil em que, às vezes, levam-se anos para que a família tenha de fato os papéis da adoção após o inicio da convivência). Falase em "rompimento ou dissolução", quando ocorre a entrega da criança após a adoção efetivada e legalizada. O segundo caso é mais grave porque entende-se que houve maior tempo de convívio e, portanto, maior dor acarretará aos envolvidos, em especial à criança ou ao adolescente. (SOUZA, 2012, p. 13).

Utilizamos o termo devolução por compreender que o estágio de convivência seja um período de extrema importância 'para a adaptação da criança à família e, não o contrário'. Entendemos que os adultos envolvidos no processo de adoção se prepararam, planejaram, tiveram a oportunidade de conhecer a história pregressa da criança, foram apresentados previamente e, enfim, 'escolheram' de forma consciente esse modo de filiação, então, a 'interrupção' desse processo foi tratada em nosso estudo como 'devolução'.

Assim, nossa pesquisa teve como objetivo compreender quais são os fatores que levam os pretendentes à adoção à devolução de crianças e adolescentes sob a sua responsabilidade durante o estágio de convivência.

Nesse sentido, em razão dos objetivos do presente estudo, que abrangem questões específicas e subjetivas, convencionou-se utilizar a pesquisa qualitativa por seu caráter exploratório que, segundo Minayo (2010), responde a questões muito particulares e se ocupa de um nível de realidade de difícil quantificação. Nessa perspectiva, trabalha com a totalidade de significados, motivos, aspirações, crenças, valores e atitudes entendidos como parte da realidade social e permite ir além da classificação e quantificação de dados, com a descoberta dos códigos sociais por intermédio das falas, dos símbolos e das observações.

Dessa maneira, os instrumentais de coleta de dados para a pesquisa foram as observações; a pesquisa 
documental - que originou estudo de caso em processo judicial no qual ocorreu a devolução de uma criança - e as entrevistas semiestruturadas com os sujeitos. Os sujeitos da pesquisa foram dois pretendentes à adoção - em estágio de convivência que expressaram o desejo pela devolução e não o fizeram - além de quatro assistentes sociais e três psicólogos, todos atuantes na área judiciária. $\mathrm{O}$ resultado da pesquisa sofreu a análise de conteúdo por intermédio de eixos temáticos.

\section{A DEVOLUÇÃO DE CRIANÇAS DURANTE O ESTÁGIO DE CONVIVÊNCIA}

Entendemos que a devolução de crianças e de adolescentes durante o estágio de convivência demonstrou ser a ponta de um iceberg de um sistema de (des) proteção social muito maior. Neste sentido, as nossas reflexões passaram por várias questões onde pode ocorrer a violação de direitos, como: a situação de acolhimento institucional, a separação da criança de sua família de origem, o processo de destituição do poder familiar, as adoções e devoluções antes e pós-adoção, as não-adoções tardias (crianças na idade acima de três anos têm mais dificuldades para ser adotadas), entre outras.

Assim, quando tratamos da adoção de crianças, acreditamos que o estágio de convivência seja uma etapa basilar para a gradual consolidação do processo de filiação; no entanto, compreender qual o seu objetivo é de fundamental importância. De acordo com a legislação, partimos do entendimento de que o estágio de convivência é o período de adaptação da criança/adolescente à família substituta e não o contrário, como é interpretado usualmente por pretendentes e, em boa parte dos casos, também pelos operadores de direito, equipes interdisciplinares da VIJ e serviços de acolhimento institucional.

Para Epaminondas da Costa, promotor do Tribunal de Justiça de Minas Gerais, o estágio de convivência, previsto no art. 46 do ECA, não pode servir de justificativa legítima para a causação, voluntária ou negligente, de prejuízo emocional ou psicológico à criança ou ao adolescente entregue para fins de adoção, especialmente diante dos princípios constitucionais da dignidade da pessoa humana e da prioridade absoluta em relação à proteção integral à infância e à juventude. Para o autor, o estágio de convivência, em síntese, é o período mínimo de avaliação da adaptação do adotando ao novo lar (família substituta), objetivando que o Poder Judiciário, com o apoio da equipe interprofissional (psicólogos e assistentes sociais etc.), decida pelo deferimento ou não da adoção (COSTA, 2009).

Assim, o estágio de convivência não pode ser visto pelos pretendentes como um 'test drive', mas como um período de adaptação da criança à família. Acreditamos que os pretendentes devam ser responsabilizados enquanto cidadãos por essa importante decisão que irá transformar as suas vidas, mas, e principalmente, a da criança. E, só depois de se posicionarem formalmente como adotantes daquela criança, ela poderá ser liberada para iniciar o estágio de convivência, no qual ela é a figura central que se adaptará ou não àquela família.

Nessa direção, compreendemos que aos pretendentes - que passam por um período de orientação e de avaliação pela equipe interprofissional - são oferecidas alternativas que podem possibilitarlhes tomar uma decisão de modo responsável, planejado, dialogado e refletido sobre essa importante transformação da vida familiar. $O$ processo de avaliação psicossocial é também uma ocasião que pode ser entendida como um momento de elaboração quanto à decisão que está sendo tomada. Atualmente há, ainda, a obrigatoriedade da participação dos pretendentes à adoção em cursos preparatórios (psicossociais e jurídicos), além de encaminhamentos para a participação em grupos de apoio à adoção, que podem colaborar para instrumentalizá-los para a futura filiação adotiva.

Entendemos que é preciso refletir que as situações de devolução de crianças e de adolescentes ao Judiciário, durante o estágio de convivência, causam graves impactos para a criança e/ou adolescentes no que tange aos aspectos emocionais, na construção de sua identidade, na 
sua relação com o mundo, nas futuras relações interpessoais, entre outros. E, segundo Ghirardi (autora bastante conhecida por seus estudos na área da psicologia sobre os processos de adoção e de devolução de crianças), "ao instaurar a ruptura do laço afetivo, a devolução significa uma experiência que reedita para a criança a sua história de abandono (...)" (2009, p. 66).

Ele desenvolveu um quadro de esquizofrenia... foi devolvido por duas vezes pela mesma família...

No caso dos dois irmãos, a menina teve depressão, fomos visitar na instituição e a menina estava a ponto de fazer alguma coisa contra ela... Suicídio...

Para a criança é péssimo! (sujeito - Psico3)

Diferentemente dos adultos, no imaginário infantil não existe estágio de convivência, documentos e/ou sentenças - para a criança, o fato de residir com a família já significa ser 'adotada': eu já encontrei a minha família... é essa a família que eu escolhi para mim! (após a família expressar o desejo de sua devolução).

Impera a necessidade de que as crianças/ adolescentes tenham a 'prioridade absoluta' e sejam colocadas em primeiro plano. Assim, destacamos a necessidade de que os adultos sejam responsáveis e comprometidos (todos, desde os representantes do Judiciário até os pretendentes) pelo processo de adoção. Nesta direção, destacamos que, no caso dos pretendentes, esse compromisso vai além daquele que se assemelha ao de um 'consumidor' que busca na loja um 'brinquedo' e que, se não gostar, poderá devolvê-lo.

A situação a seguir é bastante representativa da ideia de que a criança pode figurar como 'objeto' e não sujeito nos processos de adoção-devolução. Desse modo, enquanto (os pretendentes) declaravam o desejo de devolução, carregavam o filho recémnascido nos braços. Essa cena - passados 10 meses do estágio de convivência, com a devolução da criança ao Judiciário, sem uma justificativa plausível, no mesmo momento em que nasceu o filho do casal - nos faz pensar sobre a sociabilidade na pósmodernidade em que as relações interpessoais ocorrem na lógica semelhante à dos bens de consumo, ou seja, quando algo já não nos interessa, ficou obsoleto ou apresenta algum defeito, é rapidamente descartado ou trocado.

Nessa lógica, a criança virou coisa e, coisificada, passou a ser tratada como um objeto nas mãos de adultos que tinham o poder de decisão sobre a sua vida: a criança, colocada nesta cena, parece se tornar apenas um objeto, ou uma mercadoria, que apesar de ser educada e uma boa menina, tinha defeitos: havia mentido sobre questões escolares e furtado canetinhas da colega da escola. E, como em um processo em que a mercadoria apresenta um problema, o cliente retorna para devolvê-lo.

Questões às vezes pequenas: a criança pegou isso escondido, ou alguma reclamação da escola, ou não obedeceu, tudo isso... Coisas comuns que acontecem com qualquer criança e com qualquer família, mas que começam a se mostrar como empecilho. Transferem, na verdade a culpa e a responsabilidade para a criança, que tem dificuldades para se vincular, que mente muito, que é dissimulada, que tem que esconder a bolsa dentro de casa... Tudo isso aparece.

O impacto disso na vida da criança é devastador! A criança se sente abandonada, sim!! Verbalizou isso... Inclusive, projetou (sua raiva) nas técnicas... Em mim e na psicóloga: "vocês me fizeram acreditar que eu teria uma família e, agora, não tenho... Era mentira!!!”. Nós também fomos responsabilizadas nesse cenário todo... Ela demonstrou sentir ressentimento, mágoa, abandono, se sentia descartável... Tudo isso... (sujeito - AS1)

Nesse sentido, para tentar um melhor entendimento sobre a questão dos valores na sociedade capitalista, nos apoiamos em Barroco (2010), que ressalta:

Na sociedade capitalista, os valores éticos, estéticos, tendem a se expressar como valores de posse, de consumo, produzindo sentimentos, comportamentos e representações individualistas,

[SYN]THESIS, Rio de Janeiro, vol.7, $n^{\circ}$ 1, 2014, p. 85 - 93 
negadoras de alteridade e da sociabilidade livre. Por exemplo, o amor pode ser vivido como coisa, isto é, como algo que tem valor de troca, de consumo, de posse. A liberdade, que existe em função da capacidade deliberadora e socializadora do homem, pode se transformar objetivamente em seu oposto; pode ser vivenciada como algo que impede a sociabilidade e a autonomia. É o que ocorre quando os indivíduos vivem exclusivamente voltados ao "eu", tratando o outro como um limite à sua liberdade. Principalmente, as normas e deveres morais passam a configurar-se como exigências externas aos indivíduos; exigências que não lhes dizem respeito, mas a que devem "obedecer"; a moral se transforma num conjunto de obrigações formais, marcadas por um significado negativo, repressivo. (p. 35-36).

Temos a clareza que nem todas as situações de devolução são evitáveis e que, em muitos casos, podem vir a ser o melhor para a criança. Nesse sentido, acreditamos que buscar refletir sobre o que é possível fazer para que situações como essas sejam evitadas e, caso isso não seja possível, que ocorram de modo a produzir o menor impacto sobre a criança, é a nossa maior expectativa.

Segundo Ladvocat (2005, p. 13 apud SOUZA, 2012, p. 25)

Geralmente, a devolução ocorre nas adoções tardias, muito mais pelas dificuldades dos pais no período de adaptação, dificuldades essas embasadas nas crenças e mitos sobre a vida pré-adotiva das crianças e pelo peso da genética herdada.

(...)A família geralmente atribui determinados comportamentos às histórias de vida difíceis de serem esquecidas. Nestes casos a passagem do abrigo à casa da família deve ser acompanhada mais de perto pelos profissionais da Vara da Infância. (...) As motivações dos pais não foram devidamente conscientizadas na época da opção pela adoção e encontram barreiras da aceitação.

"Devolvem simplesmente. Se esquivam (sic) do compromisso assumido, colocando a cidadania daquele que seria seu filho num patamar social de devolvido (...). Os adultos não souberam lidar com as dificuldades e as diferenças. Será mais fácil devolver e desistir da paternagem" (SOUZA, 2012, p. 21).
Para a autora, o retorno ao abrigo, após a devolução, deve ser visto como uma dupla frustração, onde a criança sente-se culpada por não ter dado certo o convívio com a família e, ao mesmo tempo, padece pela vergonha por ter que retornar para o acolhimento institucional após um 'fracasso'.

"Tem uma tripla perda (sic): da esperança, da família e pelo fato de ficar estigmatizada, uma vez que a devolução constará em seu histórico e poderá prejudicar uma próxima adoção". (SOUZA, 2012, p. 11). E, destaca ainda,

\footnotetext{
Quem supostamente tem maturidade são os adultos, sendo, pois os responsáveis pelo sucesso da adoção da criança maior. Estas pessoas que "devolvem" serão cruéis? Egoístas ou vitimas? Como entender? Terão que reconstruir suas vidas, mas são adultos. Se livram do "incômodo" gerando problemas e confusões. O que será da criança? (SOUZA, 2012, p. 2627)
}

\section{Considerações Finais}

Ao refletir sobre os fatores que colaboram para a devolução de crianças colocadas em famílias adotivas durante o estágio de convivência - que foi o objetivo do nosso estudo - podemos elencar algumas questões.

Em primeiro plano, entendemos ser preciso criar uma cultura de convivência familiar e comunitária e não uma cultura de adoção - como pregam os diversos grupos que atuam sobre as questões relacionadas à filiação adotiva - no sentido de garantir a permanência das crianças em suas famílias naturais (de origem, ou extensa, por laços de afeto/afinidade) e que apenas em casos excepcionais sejam inseridas em famílias adotivas. Nesse sentido, inclusive, nos indagamos: por que é que temos grupos de apoio à adoção e não possuímos grupos de apoio à reintegração familiar?

Assim, esgotadas todas as possibilidades do retorno da criança à sua família de origem, percebemos a importância de avaliar se ela está preparada para essa ruptura e consequente inserção em uma família substituta. O tempo da criança, nesse caso, tem fundamental importância. Para tanto, é preciso 
respeitar o tempo de separação, de elaboração, de preparo, de construção, de esperança e de encontro com uma 'nova vida familiar'.

Por outro lado, reforçamos a necessidade de debater os aspectos relacionados à filiação adotiva nos diferentes espaços sociais. Desse modo, escolas, hospitais, universidades, centros culturais, diferentes meios de comunicação, literatura, entre outros, necessitam ser meios de veiculação de informação e de conhecimento com vistas à orientação e à redução do preconceito e da discriminação.

Salientamos que a paternidade ou a maternidade biológica pode até acontecer por acidente. No entanto, a adoção é uma escolha que deve ser planejada e refletida. Para tanto, 'os adultos' envolvidos carecem de preparo para essa importante forma de filiação.

É preciso entender que a adoção tem uma relação com diferentes sujeitos, ou seja, tem a ver com uma criança e a sua biografia, e com adultos que também têm as suas histórias peculiares (futuros pais, avós, tios, irmãos, entre outros envolvidos no processo). Os pretendentes, todos, devem se preparar para o desafio da adoção, entendendo a preparação como uma forma de fortalecimento e não como perda de tempo.

A legislação já preconiza o preparo pré-adoção (psicossocial e jurídico). Então, acreditamos na importância de buscar qualificar esse trabalho, por entender que os pretendentes também têm histórias relacionadas a dores não superadas, a exemplo: situações de infertilidade, de luto, de abortos, da idealização do filho adotivo, entre tantas outras questões. Acreditamos que é preciso trabalhar de antemão com os pretendentes para que possam preencher o berço vazio com uma criança real.

Enfim, entendemos que a devolução pode ter uma relação direta com o processo de habilitação e avaliação dos pretendentes. Não no sentido de dizer que foi feita uma boa ou má habilitação. Afinal, não basta apenas ter condições objetivas (materiais), pois, não se trata de um aspecto tão pragmático nem sequer basta atribuir culpa a quem quer que seja. Entendemos que se deve explicitar a necessidade de que as avaliações sejam criteriosas, com vistas a inverter o modelo preestabelecido de perguntas e respostas, na direção de uma maior capacidade de escuta e de percepção do não dito.

E, nos casos em que se percebam dificuldades (nas motivações, nas relações conjugais, na condução do processo, no entendimento sobre a adoção, entre tantas outras questões) é necessário investir, de diferentes formas, para um melhor preparo dos adotantes. Entretanto, destacamos o imperativo de que os avaliadores, muitas vezes vistos como inimigos dos pretendentes - o que não são - se autorizem e sejam autorizados para a evidente e óbvia condição de não habilitar aqueles que percebam não ter condições para o exercício da parentalidade.

Assim, a criança não é brinquedo, portanto, não pode ser devolvida porque derramou o leite, sujou a parede, brigou com o irmão, chorou muito, pegou canetinha do colega, ou seja, porque não atende às expectativas dos adultos. As devoluções precisam ser evitadas ao máximo e, quando isso não for possível, devem ser muito bem trabalhadas. Os adultos devem ser responsáveis, bem como responsabilizados por seus atos. Eles, os adultos, são as pessoas que devem estar preparadas para o enfrentamento da vida real, que se processa no cotidiano com a criança, também real, e não mais imaginária.

\section{REFERÊNCIAS BIBLIOGRÁFICAS}

ASSOCIAÇÃO DOS MAGISTRADOS BRASILEIROS. Cartilha Adoção de Crianças e Adolescentes do Brasil. 2009. Disponível em: <http://www.amb.com.br/ mudeumdestino/docs/Manual\%20de\%20adocao.pdf>. Acesso em: 2 jan. 2015.

BAPTISTA, M. V. Planejamento Social: intencionalidade e instrumentação. São Paulo: Veras; Lisboa: CPIHTS, 2000.

BARROCO, M. L. Ética e Serviço Social: fundamentos ontológicos. 8. ed. São Paulo: Cortez, 2010.

Ética: fundamentos sócio-históricos. 3. ed. São Paulo: Cortez, 2010.

BRASIL. Lei n. ${ }^{\circ} 8.069$, de 13 de julho de 1990. Dispõe sobre o Estatuto da Criança e do Adolescente e dá outras providências. Diário Oficial da União, Brasília, DF, 16 jul. 1990.

BRASIL. Lei n. ${ }^{\circ} 12.010$, de 03 de agosto de 2009. Dispõe sobre adoção; altera as leis n. ${ }^{\circ}$ S 8.069, de 13 de julho de 1990 -

[SYN]THESIS, Rio de Janeiro, vol.7, nº 1, 2014, p. 85 - 93 
Estatuto da Criança e do Adolescente, $\underline{8.560}$, de 29 de dezembro de 1992; revoga dispositivos da Lei n. ${ }^{\circ} 10.406$, de 10 de janeiro de 2002 - código civil, e da consolidação das leis do trabalho-CLT, aprovada pelo decreto-lei n. ${ }^{\circ} 5.452$, de $1^{\circ}$ de maio de 1943; e dá outras providências. Diário Oficial da União, Brasília, DF, 4 ago. 2009, p. 1.

COSTA, E. Estágio de convivência, "devolução" imotivada em processo de adoção de criança e de adolescente e reparação por dano moral e/ou material. In: CONGRESSO NACIONAL DO MINISTÉRIO PÚBLICO/CONAMP, 18., 2009, Florianópolis. Anais eletrônicos... Disponível em: <http:// conamp2009.com.br/?pageContent=tesesAprovadas $>$. Acesso em: 2 jan. 2015.

DINIZ, T. M. R. G. O Estudo de Caso. In: MARTINELLI, M. L. Pesquisa Qualitativa: um instigante desafio. São Paulo: Veras, 2010.

FAVERO, E. T.; MELÃO, M. J. R.; JORGE, M. R. T. O Serviço Social e a Psicologia no Judiciário: Construindo Saberes, Conquistando Direitos. 4. ed. São Paulo: Cortez, 2011.

FREITAS, M. C. (Org.). História Social da Infância no Brasil. In: MARCILIO, M. L. A roda dos expostos e a criança abandonada na História do Brasil: 1726-1950. 7. ed. São Paulo: Cortez, 2009.

GHIRARDI, M. L. A. M. A devolução de crianças e adolescentes adotivos sob a ótica psicanalítica: reedição de histórias de abandono. Dissertação (Mestrado em Psicologia)-Instituto de Psicologia, Universidade de São Paulo, São Paulo, 2008.

A devolução de crianças adotadas: ruptura do laço familiar. Revista Brasileira de Medicina, São Paulo, 2009. Disponível em: <http://www.moreirajr.com.br/ revistas.asp?fase=r003\&id_materia=3988>. Acesso em: 20 jan. 2014.

GUEIROS, D. A. Adoção consentida: do desenraizamento social da família à prática de adoção aberta. São Paulo: Cortez, 2007.

MINAYO, M. C. S. O desafio do conhecimento: pesquisa qualitativa em saúde. 7. ed. São Paulo: Hucitec, 2000.

SILVA, L. A.; MESQUiTA, D. P.; CARVALHO, B. G. E. Investigando o processo de adoção no Brasil e o perfil dos adotantes. Revista de Ciências Humanas, Florianópolis, n. 1, p. 44, abr. 2011.

SOUZA, H. P. Adoção tardia: Devolução ou desistência do filho? A necessária preparação para adoção. Curitiba: Juruá, 2012. 